VOLUME 13 NOMOR 2 TAHUN 2020

P-ISSN : 1979-9357

E-ISSN : $2620-5858$

\title{
Wawasan Alquran Tentang Pendidikan
}

\author{
Saiful Bahri \\ IAIN Lhokseumawe \\ saifulbahri@iainlhokseumawe.ac.id
}

\begin{abstract}
The Term Tarbiyah (education) that in the Quran has given deep insights into various problems, one concerning education, insights that human beings should exhume explicitly, especially in terms of the educational term, then in this case there are some verses that the author presents about the word Tarbiyah, among them the tarbiyah word in 2.S. Al Isra:24, mentioned by the word Rabbayani, in 2.S Al Rum:39, described by the word Yarbu, in Q.S Ali Imran:79, the word Rabbani and Q.S Asy Syu'ara:18 explain that the word Nurabbika"
\end{abstract}

Keyword: Al-Quran, Education, Tarbiya

Abstrak: Term Tarbiyah (pendidikan) yang tersebut dalam Al-Quran telah memberi wawasan yang mendalam berbagai masalah, salah satu mengenai pendidikan, wawasan yang harus digali oleh manusia secara eksplisit, terutama dalam hal term pendidikan, maka dalam hal ini ada beberapa ayat yang penulis sajikan tentang kata Tarbiyah, diantaranya kata tarbiyah tersebut dalam Q.S. Al Isra: 24, yang disebutkan kata Rabbayani, dalam Q.S Al Rum:39, yang dijelaskan dengan kata Yarbu, dalam Q.S Ali Imran:79, kata Rabbani dan Q.S Asy Syu'ara:18 menjelaskan bahwa kata Nurabbika"

Kata Kunci: Al Quran, Pendidikan, Tarbiyah

\section{PENDAHULUAN}

Al-Quran secara sederhana sangat lengkap dan luas penjelasannya hal ini sebagaimana yang dikemukakan oleh Syekh Ali Ash-Shabuni yaitu kalam Allah yang mu jiz, diturunkan kepada Nabi dan Rasul penghabisan dengan perantaraan Malaikat Jibril, yang dimulai dari surah Al-Fatihah dan diakhiri dengan surah AnNas"(Abidin, 2004). Secara sederhana Al-Quran dipahami sebagai sarana komunikasi Allah kepada umat manusia sehingga setiap kisah yang ada di dalamnya berfungsi sebagai pendidikan dan petunjuk serta suri tauladan serta setiap informasi pengetahuan yang ada didalamnya menjadi sumber bagi menusia untuk digali dan dipelajari.

Kalamullah ini mempunyai fungsi sebagai petunjuk atau penerang jalan hidup bagi manusia yang hidup di dunia ini, yang membedakan antara baik dengan buruk, benar dengan yang salah, yang mengarahkan manusia banyak hal kepada berbagai persoalan-persoalan tentunya yang hal utama tentang keyakinan, etika, prinsip ibadah, muamalah sampai kepada asas-asas pendidikan. Khusus mengenai pendidikan, Al-Quran menjelaskan secara mendalam tentang wawasan dan motivasi kepada manusia agar mendalami, mengkaji, memperhatikan dan meneliti isi alam sebagai manifestasi kekuasaan Allah hingga mengaplikasikan sebagai lentera hidup bagi manusia. Dari hasil pengkajian yang dilakukan oleh manusia terhadap isi dan fenomena alam sehingga melahirkan sebuah ilmu pengatahuan sebagai pondasi awal pendidikan.

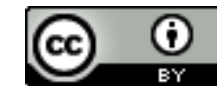

This work is licensed under a Creative Commons Attribution 4.0 International License 
VOLUME 13 NOMOR 2 TAHUN 2020

P-ISSN : 1979-9357

E-ISSN : 2620-5858

Berdasarkan pemahaman ini, tentu Al-Quran sangat berperan dalam memberikan motivator dan inspirator bagi kita untuk membaca, mengkaji serta mengemalkannya. Al-Quran juga menganjurkan umat Islam untuk bersungguhsungguh pada pencarian pendidikan, dikarenakan dunia sekarang dan bahkan dimasa yang akan datang akan dikuasai oleh IPTEK (Ilmu Pendidikan dan Teknologi), oleh sebab itu, siapa saja yang menguasai keduanya maka secara lahiriah akan menguasai dunia. Dengan kata lain pendidikan Islam itu sendiri mengarah kedua hal, yaitu, pertama membentuk mental peserta didik agar nilainilai Islam melekat pada kehidupan pribadi peserta didik. kedua agar peserta didik lebih memahami nilai-nilai Islam, maka masukkan ayat-ayat mengenai pendidikan ke dalam bidang bidang studi yang lebih banyak.(Saiful Bahri, 2016)

Perlu disadari bersama bahwa adanya isyarat al Quran tentang pendidikan sebagai bukti kebesaran mukjizatNya. Penjelasan yang terkandung dalam kalamullah ini tidak hanya terbatas pada pendidikan yang bersifat science atau bersifat empirik dan fisik sebagai fenomena, tetapi lebih dari itu, ada hal-hal yang tidak terjangkau oleh rasio manusia sebagaimana yang terkandung di dalam alQuran tentang pendidikan (at Tarbiyyah).

\section{METODE PENELITIAN}

Pembahasan pada artikel ini menggunakan kajian literatur (Hadi, 1980). Atau dengan kata lain merupakan kajian kepustakaan.

\section{HASIL DAN PEMBAHASAN}

\section{Asal usul Tarbiyah}

Mengenai makna tarbiyah ada beberapa ahli tafsir berbeda pendapat dalam mengartikan kata tarbiyah. Misalnya yang dikemukan oleh Ahmad Tafsir Tarbiyah merupakan arti dari kata pendidikan yang berasal dari tiga kata, yakni: rabba-yarbu yang bertambah, tumbuh; rabbiya-yarbaa berarti menjadi besar; dan rabba-yarubbu yang berarti memperbaiki, menguasai urusan, menuntun, menjaga, memelihara (Tafsir, 2007). Di samping itu juga istilah tarbiyah berasal dari bahasa arab, yang mana fiil tsulasi mujarrad, Rabaa yang berarti: Zaada (Bertambah), Nasya-a (Tumbuh, bertambah besar), alaha berarti: Mendaki. Adapun makna Tarbiyah dalam Lisanul Arab "Rabba, Yurabbu, Tarbiyatan" yang berarti: Malik Raja/penguasa (Munawwir, 1997).

Kalau kita baca dalam lintas sejarah kata tarbiyah ini sudah muncul sejak masa Nabi Muhammad SAW, dikala itu sudah berkembang hingga pada masa zaman keemasan Islam yaitu pada masa bani Abbas, dikala itu kata tarbiyah tak pernah muncul dalam literatur-literatur pendidikan. Namun barulah pada abad modern kata tarbiyah sudah terkenal ke permukaan sebagai terjemahan dari kata education yang dikembangkan oleh para pakar pendidikan di dunia barat. Pada saat itu, masyarakat hanya mengenal kata ta'dib sebagai kata pendidikan untuk menunjuk kepada arti pendidikan. seperti tersebut dalam hadits Nabi Muhammad SAW:

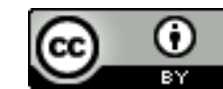

This work is licensed under a Creative Commons Attribution 4.0 International License 
VOLUME 13 NOMOR 2 TAHUN 2020

P-ISSN : 1979-9357

E-ISSN : 2620-5858

$$
\text { بيديأت نيسحأف بير ثيدأ }
$$

Artinya: Tuhan telah mendidikku sehingga pendidikanku menjadi baik

Sampai sekarang Penjelasan ta'dib ini sebagian para ahli pendidikan terus dipakai dan dikembangkan. Sehingga sampai sekarang pun yang dihasilkan oleh pakai manusia dinamakan adab, baik itu ilmu pengetahuan yang berkaitan dengan Islam (tafsir, fiqh, tauhid dan lain-lain) atau pun ilmu umum seperti fisika, matematika, kedoktoran astronomi dan lainya. Bila kita baca leteratur-leteratur sekarang, Semua buku memuat ilmu tersebut dinamai kutubul adab. Sehingga mengenal al-Adab al-Kabir dan al-Adab al-Shagir yang dikarang oleh Ibn al-Muqaffa (w. $760 \mathrm{M}$ ). Beliau adalah seorang ahli pendidik pada kala itu (sofjan: 0000). Kemudian ilmu pengetahuan terus berkembang mengikuti perkembangan zaman, ketika para ahli pendidikan memusatkan pada satu bidang keahlian dalam suatu ilmu pengetahuan, maka penjelasan adab sudah terbatas, yaitu hanya dipakai untuk menunjuk kesusastraan dan etika;sehingga dampaknya ta'dib sekarang sebagai penjelasan konsep pendidikan Islam sudah hilang dari peredaran dan tidak dipakai lagi, namun sekarang banyak para ahli pendidik Islam menggunakan istilah education yang dipelopori oleh dunia barat, sehingga sekarang mereka menggunakan kata istilah tarbiyah, walaupun penjelasan pendidikan dalam Islam tidak sama istilahnya dengan education yang dicetuskan oleh dunia Barat.

Term yang sangat terkenal yang sering digunakan oleh para ahli, khususnya para pakar pendidikan Islam dalam memberikan makna pendidikan Islam itu sendiri, sekarang banyak menggunakan istilah term al-Tarbiyah. Sedang term alTa'dib, al-Ta'lim, riyadloh, irsyad, dan tadris jarang sekali digunakan. Padahal istilahistilah tersebut dari awal perkembangan Islam telah digunakan pertumbuhan pendidikan Islam (Halim, 2002). Di samping itu menurut Abudin Nata sebenarnya banyak istilah yang dianggap mendekati makna pendidikan, diantaranya AlTarbiyah, At-Ta'lim, At-Ta'dib atau al Adab, At-Tahzib, Al-Wa'adz atau Mau'idzah, ArRiyadhah, At-Tazkiyyah, Al-Talqin, At-Tadris, At-Tafaqquh, At-Tabyin, At-Tazkirah, AlIrsyad (Nata, 2010)

Sebagaimana dijelaskan oleh Karman dalam bukunya, bahwa Tarbiyyah secara etimlogi merupakan bentuk masdar dari kata Rabba, kendati pun walapaun tidak disebutkan secara eksplisit dalam al qur'an, tetapi term turunannya seperti al-rabb, rabbayani, nurabbi, rabbiyun dan rabbni berjumlah cukup banyak dalam al qur'an (Karman, 2018). Di sisi lain kata tarbiyyah sebagaimana dijelaskan oleh Naquib al-Atas yang dikutip oleh Ramayulis berpendapat. Semenjak datangnya Islam makna pendidikan sudah digunakan pada saat itu, namun pada waktu itu hanya dipakai dua istilah saja, yaitu tarbiyah dan ta'dib. Kata tarbiyah tidak secara khusus ditujukan untuk mendidik manusia, akan tetapi banyak dipakai kepada spesies lain seperti mineral, tanaman dan hewan. Sedangkan istilah ta'dib mengarah pada pengertian ('ilm), pengajaran (ta'lim) dan bimbingan yang baik (tarbiyah). Jadi, tarbiyah dalam penjelasan Naquib hanya salah satu bagian dari ta'dib

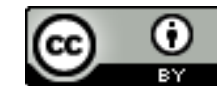

This work is licensed under a Creative Commons Attribution 4.0 International License 
VOLUME 13 NOMOR 2 TAHUN 2020

P-ISSN : 1979-9357

E-ISSN : 2620-5858

(Ramayulis, 1994). Dari penjelasan ini menurut penulis, Naquib lebih cenderung menggunakan Ta'dib sebagai pendidikan bukan kata tarbiyah.

Namun demikian, para ahli pendidikan dulu seperti Muhammad At Toumy, Al-Syaibany, Munir Mursyi, athiyah Al Abrasyi, Ahmad Tsalabi, Muhammad Qutub, Ali Khalil Abul Ainain, Ibn Sina, ibn Taimiyah dan masih banyak lagi mereka lebih suka menggunakan kata Tarbiyyah dalam pengertian pendidikan ketimbang kata lain (Nata, 2010). Di samping itu, hasil dari seminar internasional yang pertama pendidikan Islam yang dilaksanakan di Jeddah pada tahun 1977, yakni (First World Conference on Muslim Education) di Universitas King Abdul Aziz, menghasilkan bahwa pendidikan menurut Islam dapat didefinisikan dalam tiga istilah, yaitu Tarbiyah, Ta'lim dan Ta'dib secara bersama-sama (Tafsir, 2012). Kendatipun demikian, apabila al tarbiyyah diindektikan dengan al Rabba, maka al tarbiyah berarti pemilik, tuan, yang maha memperbaiki, yang maha mengatur, yang maha mengubah dan yang maha menunaikan (Qurtubi, n.d.) Term al tarbiyyah pada dasarnya pengertian yang sangat luas, selain tersebut di atas ada juga pengertianya sebagai menguasi, memelihara, memberi makan, menumbuhkan, mengembangkan dan juga mendidik, ini yang cukup luas maknanya.

Selanjutnya sebagaimana yang dijelaskan oleh Ar Raghib al Ashfaniy menafsirkan Rabb adalah tuhan yang mendidik yang meperkuat orang yang di didik dan mengatur keadaan mereka. Pendidikan yang diberikan Allah kepada manusia terbagi dua, yaitu pendidikan fisik yang dikembangkan melalui jasmani sehingga mencapai keadaan yang kukuh serta mengembangkan kekuatan jiwa dan akalnya. Dan yang kedua pendidikan keagamaan dan budi pekerti yang mengembangkan dengan cara menyampaikan ajaran agama kepada setiap orang sehingga sempurna aklanya bersih jiwanya sehinnga manusia bersih dalam menyembah Allah SWT (Maraghy, n.d.). Dari pengertian tersebut di atas, maka pengertian pendidikan Islam secara luas dapat kita temukan dalam term al- Tarbiyah yang terdapat didalamnya 4 unsur, yaitu:

a) Memelihara serta menjaga fitrah anak didik menjelang dewasa.

b) Mengembangkan serta mengaplikasikan seluruh potensi kedalam lingkungan menuju kesempurnaan

c) Mengarahkan serta mengimplimentasikan seluruh fitrah menuju kesempurnaan.

d) Melaksanakan pendidikan secara lengkap.(Ridwan, 2018)

\section{Ayat Ayat tentang at Tarbiyah dalam Al quran}

Kalau berbicara mengenai Alquran tentu kita akan berbicara tentang pendidikan juga, karena dalam al quran justru lebih banyak membahas tentang pendidikan. Hal ini sebagaimana dijelaskan oleh Atiqa, bahwa sebenarnya al qur'an itu sudah sempurna sekali, ayat-ayat yang diturunkan kepada nabi Muhammad saw tersebut sesungguhnya telah berisi petunjuk, rahmat, penjelasan, pembeda dan obat bagi manusia sebagai aturan hidup didunia supaya jangan tersesat. (Azizah, 2018). Untuk pembahasan lebih lanjut, mari kita bahas ayat-ayat mengenai pendidikan (tarbiyah).

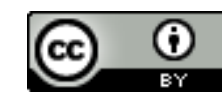

This work is licensed under a Creative Commons Attribution 4.0 International License 
VOLUME 13 NOMOR 2 TAHUN 2020

P-ISSN : 1979-9357

E-ISSN : $2620-5858$

\section{Term tarbiyah dalam surat Al Isra ayat 24.}

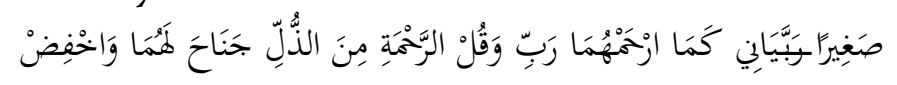

Artinya: "Dan rendahkanlah dirimu terhadap mereka berdua dengan penuh kesayangan dan ucapkanlah: "Wahai Tuhanku, kasihilah mereka keduanya, sebagaimana mereka berdua telah mendidik aku waktu kecil"(2.S. Al Isra' Ayat 24).

Quraish Shihab menerangkan bahwa tuntutan bakti kepada ibu bapak dan melebihi tuntutan sebelumnya. Ayat ini memerintahkan dengan redaksinya "dan rendahkanlah dirimu terhadap mereka berdua didorong oleh karena rahmat kasih sayang kepada keduanya, bukan karena malu dicela orang lain. Dan hendaklah seorang anak berdoa dengan tulus "Wahai Tuhanku, kasihilah mereka keduanya, disebabkan karena mereka berdua telah mendidikku telah waktu kecil". Kata (جناح) janâh pada ayat itu menurut Quraish Shihab pada mulanya berarti sayap. Seekor burung akan merendahkan sayapnya saat ia melindungi anak-anaknya. Sayapnya terus dikembangkan dengan merendah dan merangkul, serta tidak beranjak meninggalkan tempat sampai anak-anaknya aman dari ancaman bahaya. Mengambil contoh prilaku burung dalam melidungi anaknya, maka ungkapan itu dipahami dalam arti kerendahan hati, hubungan harmonis serta perlindungan dan ketabahan (Shihab, 2002)

Lebih lanjut Doa yang diperintahkan untuk dipanjatkan bagi ibu bapak dipahami oleh sebagian ulama dalam arti disebabkan karena mereka telah mendidikku di waktu kecil dan bukan seperti umumnya diterjemahkan yaitu sebagaimana mereka telah mendidikku waktu kecil. Argumennya adalah karena jika rahmat yang dimohonkan untuk dianugerahkan bagi ibu bapak redaksinya sebagaimana mereka telah mendidikku sewaktu kecil, maka rahmat yang dimohonkan itu kualitas dan kuantitasnya sama dengan apa yang kita peroleh dari kedua orang tua, tetapi bila redaksinya "disebabkan karena mereka telah mendidikku sewaktu kecil, maka rahmat yang dimohonkan kita serahkan kepada kemurahan Allah dan ini dapat melimpah jauh lebih banyak dan besar daripada apa yang telah dilimpahkan oleh kedua orang tua limpahkan pada kita (Shihab, 2002)

Dalam Q.S Al-Isra Ayat 24 di atas tidak diterangkan siapakah yang harus didahulukan mendapat bakti anatara kedua Ibu-Bapak akan tetapi dalam sebuah hadis di jelaskan bahwa berbakti kepada ibu di dahulukan daripada kepada Bapak seperti di riwayatkan dalam Sahih Bukhari dan Muslim di bawah ini: yang artinya Dari Abu Hurairah radhiyallahu 'anhu dia berkata; "Seorang laki-laki datang kepada Rasulullah shallallahu 'alaihi wasallam sambil berkata; "Wahai Rasulullah, siapakah orang yang paling berhak aku berbakti kepadanya?" Beliau menjawab: "Ibumu." Dia bertanya lagi; "Kemudian siapa?" Beliau menjawab: "Ibumu." Dia bertanya lagi; "Kemudian siapa lagi?" Beliau menjawab: "Ibumu." Dia bertanya lagi; "Kemudian siapa?" Beliau menjawab: "Kemudian ayahmu." (HR. Bukhari dan Muslim).(RI, n.d.) 
VOLUME 13 NOMOR 2 TAHUN 2020

P-ISSN : 1979-9357

E-ISSN : 2620-5858

Di samping itu juga penjelasan ayat tersebut di atas menurut Ahmad Al Hasyimiy dijelaskan bahwa, yaitu pendidikan yang diberikan oleh kedua orang tua kepada anaknya, maka seorang anak harus menunjukkan sikap hormat dan terima kasih dengan cara bersikap tawadhuk (rendah hati) dan mendo'akan kebaikan keduanya, sikap anak yang mendo'akan kepada kedua orang tuanya tersebut dikatakan sebagai anak yang shaleh, sebagai mana juga dijelaskan dalam hadih Nabi saw:

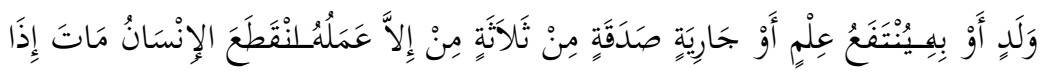

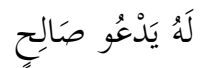

Artinya: "Jika seorang manusia meninggal dunia, maka putuslan segala amalnya, kecuali tiga perkara, yaitu sedekah jariah, ilmu yang bermanfaat dan anak yang mendo'akan kepada orang tuanya. (HR. Muslim r.a)"(Bek, 1948)

Oleh karena itu pembahasan di atas dapat kita pahami bahwa tarbiyah mengadung makna menumbuhkembangkan akal, mental dan fisik seorang anak yang melahirkan suatu proses kasih sayang serta kelembutan hati sampai anak tersebut bisa hidup mandiri dan bisa mempertahankan jati dirinya di tengah-tengah masyarakat yang hidup tanpa batas terhadap pergaulan dan sikap dizaman sekarang ini. sehingga anak harus mengasihani serta menyayangi kedua orang tuanya dan berdo'a agar Allah memberikan rahmat dan ridhaNya kepadanya yang telah mendidik anaknya tanpa batas dari kecil hingga besar. Dengan kata lain setiap orang tua senantiasa mendidik anaknya sejak kecil dengan penuh kasih sayang sehingga anak tersebut mencapai usia dewasa sehingga hidup bisa mandiri.

\section{Term Tarbiyah dalam surat ar Rum ayat 39}

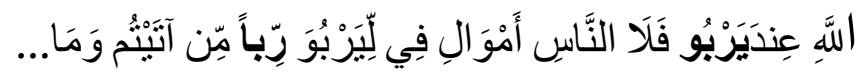

Artinya: Dan sesuatu riba (tambahan) yang kamu berikan agar dia bertambah pada harta manusia, maka ribaitu tidak menambah pada sisi Allah... (Q.S. Ar Rum: 39)

Quraish Shihab menjekaskan bahwa, kata "yarbu" berasal dari fi'il "rabaayarbu-rabaan" yang berarti "bertambah". Kata "ribaa" dari segi bahasa berarti kelebihan. Yang dimaksudkan dalam ayat tersebut disamakan dengan kata "riba" yakni bertambahnya harta (Shihab, 2002). Namun di sisi lain kata riba ditemukan delapan kali dalam empat surat dalam Al-Quran. Salah satu dalam surat Ar Rum ini yang ditulis tanpa menggunaakn huruf wawu, ditulis (ربا)( لربا) Sedang, selainnya ditulis dengan huruf wawu yakni (الربو)

\section{Term Tarbiyah dalam surat Ali Imran ayat 79}

Dalam ayat ini menjelaskan bahwa tarbiyah juga berasal dari kata "Rabbani", hal ini dapat dilihat dari potongan dalam surat Ali Imran ayat 79.

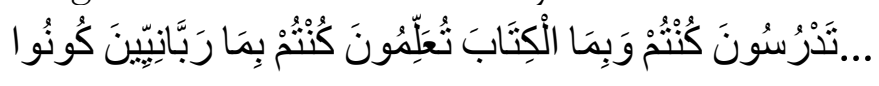


VOLUME 13 NOMOR 2 TAHUN 2020

P-ISSN : 1979-9357

E-ISSN : 2620-5858

Artinya: ..."Hendaklah kamu menjadi orang-orang rabbani, karena kamu selalu mengajarkan Al Kitab dan disebabkan kamu tetap mempelajarinya."(2.S. Ali Imran: 79)

Namun dalam ayat tersebut terdapat kata rabbani yang terambil dari kata rabba yang memiliki banyak makna yakni pendidik atau pelindung. Disini adanya penisbatan terhadap sesuatu dengan menambahi huruf ya' seperti kata insaan menjadi insaani atau kata nur menjadi nuur, atau bisa ditambahi sebelum huruf $y a^{\prime}$ dengan alif and nun maka jika dari kata rabba menjadi rabbani sebagaimana bunyinya dalam ayat di atas. Adapun maksud dari kata rabbani bermakna orang yang sempurna ilmu dan takwanya kepada Allah s.w.t atau, bisa dikatakan (orang yang terus menerus mengajarkan kitab suci, atau terus menurus mempelajari (Shihab, 2002)

\section{Term Tarbiyah dalam surat Asy Syu'ara ayat 18}

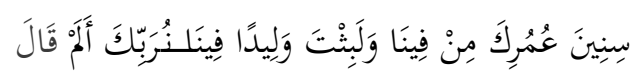

Artinya: "Fir'aun menjawab: "Bukankah Kami telah mengasuhmu di antara (keluarga) Kami, waktu kamu masih kanak-kanak dan kamu tinggal bersama Kami beberapa tahun dari umurmu" (Q.S Asy Syu'ara:18)

Quraish Shihab menguraikan ayat tersebut, kata "nurabbika" dari bentuk fi'il "rabba-yarubbu-rabban" memiliki arti "mendidik atau mengasuh". Maksud ayat tersebut adalah kisah pengasuhan Fir'aun terhadap Nabi Musa as. ketika bayi hingga besar (Shihab, 2002). Di samping term Pendidikan (at tarbiyyah) dalam al qur'an, juga dalam hadis nama dijelaskan tentang term rabbani hal ini dapat dilihat sebagai mana sabda Nabi Saw, melalui riwayat Ibn Abbas:

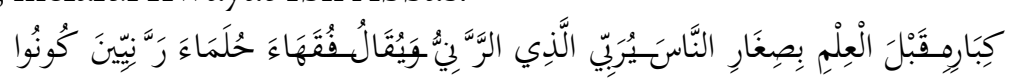

Artinya: Dari Ibn Abbas, Nabi saw. bersabda: "Jadilah kalian para pendidik yang penyantun (hulama) ahli Ilmu (fuqaha) dan berilmu (Ulama) seseorang dikatakan rabbani apabila ia telah mendidik seseorang dengan ilmu dari yang sekecil-kecilnya menuju yang tinggi"(shahih Bukhari)

Berdasarkan hadis tersebut, tentu kata al rabbani identik dengan at tarbiyah, berarti proses transformasi ilmu pengetahuan yang dilakukan secara bertahap. Proses tersebut dilakukan sebagai pengenalan, hafalan dan ingatan yang belum terjangkau proses pemahaman dan penalaran, hal ini bila ditinjau dalam kontek sejarah awal muncul Islam, Nabi Muhammad saw. merupakan pendidik yang pertama ketika beliau 13 tahun di Mekkah, pendidikan hal ini dinyatakan sebagai akar kata rabba yurabbi (Syadid, n.d.)

\section{KESIMPULAN}


VOLUME 13 NOMOR 2 TAHUN 2020

P-ISSN : 1979-9357

E-ISSN : 2620-5858

Berdasarkan berbagai penjelasan di atas secara umum kata tarbiyah dapat dikembalikan kepada tiga kata kerja yang berbeda dan mempunyai kaitan makna Pertama, raba yang berarti berkembang; kedua, nama yanmu yang berarti tumbuh, dan ketiga dari kata rabba-yaribbu yang berarti memperbaiki, mengurus, memimpin, menjaga, memelihara atau mendidik. Al-Tarbiyah adalah proses pengembangan, pemeliharaan, penjagaan, pengurusan, penyampaian ilmu, pemberian petunjuk, bimbingan, penyempurnaan, dan perasaan memiliki bagi anak didik baik jasad, akal, jiwa, bakat, potensi, perasaan, secara berkelanjutan, bertahap, penuh kasih sayang, penuh perhatian, kelembutan hati, menyenangkan, bijak, mudah diterima, sehingga membentuk kesempurnaan fitrah manusia, kesenangan, kemuliaan, hidup mandiri, untuk mencapai ridha Allah swt.

\section{DAFTAR PUSTAKA}

Abidin, Z. (2004). Seluk Beluk Al-Qur'an. Reneka Cipta.

Azizah, A. (2018). Konsep Tarbiyah Dalam Islam. ANALYTICA ISLAMICA, Vol. 7 (1), 1-15.

Bek, A. S. A. A. H. (1948). Mukhtar al Ahadist an Nabawiyyah wa al Hikmah al Muhammadiyah. Mathba'ah Hijazy bi al Qahirah.

Halim, A. (2002). Filsafat Pendidikan Islam: Pendekatan Historis, Teoris dan Praktis. Ciputat Press.

Karman. (2018). Tafsir Ayat-Ayat Pendidikan. Rosdakarya.

Maraghy, A. M. al. (n.d.). Tafsir al Maraghy aj Juzal -Awwal. Dar Al Fikr.

Munawwir, A. W. (1997). Kamus Al Munawwir. Pustaka Progressif.

Nata, A. (2010). Ilmu Pendidikan Islam. Kencana.

Qurtubi, I. A. M. B. A. al A. Al. (n.d.). Tafsir Al Qurtubi. Durus Al Syab.

Ramayulis. (1994). Ilmu Pendidikan Islam. Kalam Mulia.

RI, D. A. (n.d.). Al-Qur'an dan Tafsirannya. Dana Bakti Wakaf.

Ridwan, M. (2018). Konsep Tarbiyah, Ta'lim dan Ta'dib Dalam Al- Qur'an. Nazhruna: Jurnal Pendidikan ISlam, 1(1), 37-60.

Saiful Bahri. (2016). KONSEP PENDIDIKAN ISLAM MENURUT FAZLUR RAHMAN. Sarwah: Jurnal Pencerahan Intelektual Muslim, XV(I), 119-128.

Shihab, Q. (2002). Tafsir Al-Misbah,. Lentera Hati.

Syadid, M. (n.d.). Manhaj Al qur'an Fil al-Tarbiyyah. tt.

Tafsir, A. (2007). Ilmu Pendidikan Dalam Perspektif Islam. Remaja Rosda Karya.

Tafsir, A. (2012). Ilmu Pendidikan Islam. Remaja Rosda Karya. 